www.jmscr.igmpublication.org

Index Copernicus Value: 79.54

ISSN (e)-2347-176x ISSN (p) 2455-0450

crossref DOI: https://dx.doi.org/10.18535/jmscr/v7i5.109

Journal Of Medical Science And Clinical Research

\title{
Use of Intrathecal dexmedetomidine and fentanyl as adjuvants to low dose spinal anesthesia with levobupivacaine in patients undergoing transurethral resection of prostrate -A Comparative study
}

Authors

\author{
Dr Praveen Kumar Moturi ${ }^{1}$, Dr Yogitha Devi Allu ${ }^{2^{*}}$, Dr Gunaseelan.C ${ }^{3}$, Dr Avinash . $\mathbf{R}^{4}$ \\ ${ }^{1,2}$ Assistant Professor, Department of Anaesthesiology, Andhra Medical College, Vishakapatnam \\ ${ }^{3}$ Resident, Department of Anaesthesiology, Andhra Medical College, Vishakapatnam \\ ${ }^{4}$ Senior resident, Department of Anaesthesiology, Andhra Medical College, Visakhapatnam \\ *Corresponding Author \\ Dr Yogitha Devi Allu
}

Assistant Professor, Department of Anaesthesiology, Andhra Medical College, Vishakapatnam, India

\begin{abstract}
Purpose of the study: Patients undergoing transurethral resection of prostate are usually elderly patients with unstable hemodynamics. As far as transurethral resection of prostate cases are concerned, anesthesia level up to T10 dermatome is sufficient. This will minimize the hemodynamic alterations in geriatric age group. So the aim is to use low dose spinal anesthesia but this low dose spinal anesthesia alone using single drug levobupivacaine does not provide sufficient surgical anesthesia. So addition of adjuvants was considered. The aim of the study was to compare the adjuvant effects of intrathecal dexmedetomidine and intrathecal fentanyl with low dose levobupivacine spinal anesthesia.

Methods: Comparative study was double blinded randomized trial which included 60 patients of ASA grade I,II,III posted for transurethral resection of prostate. They were divided into two groups. Group D receiving Dexmedetomidine and Group F receiving Fentanyl with low dose levobupivacaine intrathecally Outcomes which were compared between two groups were characteristics of block; hemodynamical changes intra-operatively and post-operative analgesic requirements.

Results: Baseline demographic attributes were comparable. peak sensory levels were similar in both groups $D$ and $F$ around T8. Group D has quicker onset of sensory block than group F.

[Group D $10.7 \pm 2.24$ min][Group F $11.8 \pm 1.75 \mathrm{~min}$ ]

Duration of block was more in group D $(197.033 \pm 12.71 \mathrm{~min})$ compared to Group F with $(187.8 \pm 8.23 \mathrm{~min})$ The requirement of first analgesic dose was based on VAS score. It was delayed in Group D where the mean time of analgesic requirement was $(212.033 \pm 15.07 \mathrm{~min})$ where as in fentanyl it was $(200.27 \pm 7.45$ min).

Conclusion: Intrathecal dexmedetomidine with low dose levobupivacaine provided faster onset of anesthesia with increased duration of sensory and motor block. The duration for rescue analgesic requirement was more in group D with lower post-operative VAS scores. However, the haemodynamics in both groups were similar.

Keywords: Adjuvants, levobupivacaine, dexmedetomidine, fentanyl, spinal anesthesia, TURP.
\end{abstract}




\section{Introduction}

The most common problem encountered in geriatric population is benign prostatic hypertrophy. Unstable hemodynamics during anesthesia is common in this age group. Spinal anesthesia is the most commonly used technique for transurethral resection of prostate.

A block up to T10 is considered sufficient in patients undergoing TURP as this will abolish the discomfort of bladder distension and gross hemodynamic changes.

Any block beyond T10 will mask the early diagnosis of capsular signs due to bladder perforation. So in our study we used smaller doses of local anesthetic with adjuvants which provides adequate motor and sensory block.

Dexmedetomidine is the s-enantiomer of medetomidine which has not been widely used in urological procedures while fentanyl is the synthetic opioid whose use has been rise in recent days.

Levobupivacaine is the s-enantiomer of bupivacaine belonging to amino-amide group. It is comparatively less cardiotoxic. Hence, the use of levobupivacaine for spinal anesthesia is increasing these days.

In this study we tried to compare the characteristics of spinal block, hemodynamic changes and analgesic requirements.

In Group-D, $5 \mu \mathrm{g}$ of Dexmedotomidine was used as adjuvant to $10 \mathrm{mg}$ ( $2 \mathrm{ml}$ ) isobaric levobupivaciane and in Group F $25 \mu \mathrm{g}$ of Fentanyl was used as adjuvant to $10 \mathrm{mg}(2 \mathrm{ml})$ of levobupivacaine.

\section{Methods}

Study was double blinded, prospective randomized was conducted in King George Hospital, Visakhapatnam between February 2018 to May 2018. Informed Consent was taken from all patients

Sixty elderly male between age group 50 to 80 years and ASA grade I, II, III who were posted for TURP were included in the study. Patients were randomly allocated into two groups, Group D and Group F. Patients with history of spine surgery, bleeding disorders and coagulopathy, allergic reactions to local anaesthetics were excluded from the study.

In Group D consisting of thirty patients $2 \mathrm{ml}$ $(10 \mathrm{mg})$ of $0.5 \%$ isobaric levobupivacaine with $0.5 \mathrm{ml}(5 \mu \mathrm{g})$ of dexmedetomidine hydrochloride as adjuvant was used in spinal anesthesia.

In Group F (thirty patients) $2 \mathrm{ml}$ (10mg) $0.5 \%$ isobaric levobupivacaine with $0.5 \mathrm{ml}(25 \mu \mathrm{g})$ Fentanyl as adjuvant was used. The anesthesiologists involved in the study were not aware of the adjuvant being used until the entire sixty patients were completed according to the randomized numbers allotted to the patients.

All the patients were kept nil oral from mid night. They were administered T. Alprazolam $0.25 \mathrm{mg}$ in the night before surgery.

Inj. Ondansetron 4mg and Inj Metoclopramide 10mg, Inj. Ranitidine 50mg were given 30min. before surgery.

The patients were then brought to operation theatre. Intravenous lines were secured. Preloading was started with normal saline. Noninvasive Blood pressure monitoring, peripheral oxygen saturation monitor and ECG were attached. All the baseline vitals were noted. Study drug solution used in both groups D and F was identical with same $2.5 \mathrm{ml}$ volume. Drug solution was prepared by anesthetist who was not involved in the study.

Dexmedetomidine $1 \mathrm{ml}$ diluted to $10 \mathrm{ml}$ with normal saline so that each $\mathrm{ml}$ contains $10 \mu \mathrm{g}$, out of each $0.5 \mathrm{ml}$ i.e., $5 \mu$ of Dexmedetomidine was taken and added to $2 \mathrm{ml}$ of isobaric Levobupivaciane. Total $2.5 \mathrm{ml}$ solution was prepared. Similarly $0.5 \mathrm{ml}$ of undiluted fentanyl amounting to $25 \mu \mathrm{g}$ was added to $2 \mathrm{ml}$ isobaric levobupivacaine thus making it to $2.5 \mathrm{ml}$

Preparation of both solutions was done in strict aseptic precautions. Help was taken from colleague anesthetists and post graduate students who were unaware of the study to monitor all aspects of the study like.

a) Characteristics of spinal block

b) Incidence of adverse events 
c) Analgesic requirements in two groups

\section{Assessment of Characteristics of Spinal Block}

After giving spinal anesthesia following strict aseptic precautions, level of anaesthesia was checked and after attaining T10 level surgeon was asked to proceed. Then assessment was done every 30minutes to assess for the regression of spinal anaesthesia. Regression by two segments was taken as criteria. Motor block was assessed by using modified Bromage scale before the start of surgery and at the end of surgery followed by every 30 minutes until complete motor recovery. If patient complains of pain or discomfort, $100 \mu$ fentanyl was given and attempted to continue the procedure failing which general anesthesia was given and the patient was eliminated from our study.

\section{Post Operative Pain Assessment and Analgesic Requirement}

VAS $\rightarrow 11$ Point visual analogue scale

\section{0 -No pain}

10 -worst pain was used for pain assessment.

Inj. Butarphanol. 1mg I.V. was used as rescue analgesic when the patient needed. Assessment of pain was done every $2^{\text {nd }}$ hourly until 24 hours post operatively.

Time for first analgesic dose was noted.

\section{Adverse Events}

Heart Rate below 45 was considered as bradycardia and Mean arterial pressure < 60 was considered as Hypotension. Bradycardia and Hypotension were noted and treated accordingly with Inj. Atropine and Inj. Mephenteramine. For patients complaining of nausea and vomiting, Inj. Ondansetron $4 \mathrm{mg}$ I.V. given. Intra operative Respiratory Depression if any was treated with mask ventilation and case was excluded from study.

\section{Statistical Methods}

The main derivative of the study was duration of sensory block assessed by time of regression of two dermatomes levels from initial level. This was taken from a previous study(s).

In group $\mathrm{D}$ the mean time $\pm \mathrm{SD}$ to the sensory regression of two dermatomes from highest level was $125.833+/-9.88 \mathrm{~min}$. while in Group Fit was120+/-5.20 min in previous study. Sample size was calculated using an $\alpha=0.05$ and power of $80 \%$ which come up to 24 patients required for group to detect or $25 \%$ difference in time for 2 segment dermatome regression of sensory Block.

So in our study we involved thirty patients per group to allow for possible drop out.

Student t-test was used to analyse age; weight, duration of surgery, duration of Sensory and Motor Block; VAS scores every hourly upto 4 hours, total duration of Analgesia and requirement of rescue analgesic first dose. The differences between two groups in various derivatives were tested with many Man-whitney $\mathrm{U}$ test. $\mathrm{Z}$ test i.e., test of proportion was used to test the significant differences between two groups. Values were expressed as mean \pm SD. $\mathrm{p}<0.05$ was considered statistically significant.

\section{Results}

The Demographic variables like age; weight, ASA physical status in both groups were comparable and there is no significant statistical difference between the two groups.

Table 1:

\begin{tabular}{|l|c|c|c|}
\hline CHARACTERISTICS & $\begin{array}{c}\text { GROUP D } \\
(\mathrm{n}=30)\end{array}$ & $\begin{array}{c}\text { GROUP F } \\
(\mathrm{n}=30)\end{array}$ & $\begin{array}{c}\text { P } \\
\text { VALUE }\end{array}$ \\
\cline { 1 - 3 } AGE(YEARS) & $57.8 \pm 4.31$ & $58.2 \pm 4.78$ & 0.7348 \\
\hline WEIGHT( IN KGS) & $65.567 \pm 11.18$ & $66.06 \pm 11.76$ & 0.8684 \\
\cline { 1 - 2 } $\begin{array}{l}\text { DURATION OF } \\
\text { SURGERY(MINS) }\end{array}$ & $82.93 \pm 7.07$ & $83.43 \pm 7.31$ & 0.7887 \\
\cline { 1 - 1 } ASA PHYSICAL STATUS & $11(36.7)$ & $20(66.7)$ & \multirow{2}{*}{1.0000} \\
\cline { 1 - 1 } GRADE I & $17(56.7)$ & $9(30)$ & \\
\cline { 1 - 2 } GRADE II & $2(6.6)$ & $1(3.3)$ & \\
\cline { 1 - 2 } GRADE III & & &
\end{tabular}

The mean time taken to reach T10 sensory Block was $(10.70 \pm 2.24 \mathrm{~min})$ was lower in Group D than with Group F which was $(11.8 \pm 1.75 \mathrm{~min})$ which is comparable and statistically significant. Peak sensory Block levels were similar in both groups D \& F while the maximum level of sensory block achieved in both groups was T8. 
Duration of two segment regression of sensory block was higher in Group D (125.833 \pm 9.88$)$ and in Group F (120.7 $\pm 5.20 \mathrm{mins})$ was Significant (P $=0.0146$ ).

Motor Block lasted for a longer duration in Group D $(197.033 \pm 12.71 \mathrm{~min})$ than in Group $\mathrm{F}$ $(187.8 \pm 8.23 \mathrm{~min})$ and it was statistically significant $(\mathrm{p}=0.0015)$.

Duration of first analgesic requirements with Group D $(212.033 \pm 15.07 \mathrm{~min})$ while in Group F it in (200.667 $\pm 7.44 \mathrm{~min})$ which is comparable and statistically significant $(\mathrm{p}=0.0005$

Table 2

\begin{tabular}{|c|c|c|c|}
\hline CHARACTERISTICS & $\begin{array}{c}\text { GROUP D } \\
(\mathrm{n}=30)\end{array}$ & $\begin{array}{l}\text { GROUP F } \\
(\mathrm{n}=30)\end{array}$ & $\begin{array}{c}\text { P } \\
\text { VALUE }\end{array}$ \\
\hline $\begin{array}{l}\text { Time to reach } \mathrm{T}_{10} \\
\text { sensory block }\end{array}$ & $10.7 \pm 2.24$ & $11.8 \pm 1.75$ & 0.0383 \\
\hline $\begin{array}{l}\text { Peak sensory level } \\
\mathrm{T}_{8} \\
\mathrm{~T}_{10} \\
>\mathrm{T}_{10}\end{array}$ & $\begin{array}{c}14(46.67) \\
10(33.33) \\
6(20)\end{array}$ & $\begin{array}{c}15(50) \\
14(46.7) \\
1(3.3)\end{array}$ & 1.000 \\
\hline $\begin{array}{l}\text { Modified Bromage Scale } \\
\text { At The End Of Surgery } \\
0 \\
1 \\
2 \\
3\end{array}$ & $\begin{array}{c}0 \\
3(10) \\
12(40) \\
15(50)\end{array}$ & $\begin{array}{c}0 \\
0 \\
16(53.3) \\
14(46.7)\end{array}$ & 0.896 \\
\hline $\begin{array}{l}\text { TIME TO } \\
\text { SEGMENT } \\
\text { REGRESSION (MIN) } \\
\text { REO }\end{array}$ & $125.833 \pm 9.88$ & $120.7 \pm 5.207$ & 0.0146 \\
\hline $\begin{array}{l}\text { TIME TO MOTOR } \\
\text { RECOVERY (MIN) }\end{array}$ & $197.033 \pm 12.71$ & $187.8 \pm 8.23$ & 0.0015 \\
\hline $\begin{array}{l}\text { TIME TO FIRST } \\
\text { POSTOPERATIVE } \\
\text { ANALGESIC } \\
\text { REQUIREMENT }\end{array}$ & $212.033 \pm 15.07$ & $200.667 \pm 7.44$ & 0.0005 \\
\hline
\end{tabular}

Data represented as mean $\pm \mathrm{SD}$ or number of patients n (\%) SD- Standard Deviation

\section{Comparison of Visual Analogue Scale}

\begin{tabular}{|l|c|c|c|}
\hline VAS SCORE & GROUP D & GROUP F & P \\
\hline 1 HOUR POST SURGERY & $1.60 \pm 0.62$ & $2.36 \pm 0.67$ & $<0.0001$ \\
\hline 2 HOUR POST SURGERY & $2.03 \pm 0.49$ & $2.8 \pm 0.89$ & 0.0001 \\
\hline 3 HOUR POST SURGERY & $2.53 \pm 0.57$ & $3.1 \pm 0.92$ & 0.0101 \\
\hline 4 HOUR POST SURGERY & $3.13 \pm 0.73$ & $3.63 \pm 076$ & 0.0118 \\
\hline
\end{tabular}

Group D patients had low postoperative VAS score and reduced analgesic requirements.

\section{Intra operative Side Effects}

None of the patients developed severe Complications like severe hypotension (MAP < $60)$. While very few patients reported nausea and shivering which were treated with Inj. Ondansteron 4mg. None developed respiratory depression.

\begin{tabular}{|l|c|c|c|}
\hline SIDE EFFECTS & $\begin{array}{c}\text { GROUP D } \\
(\mathrm{n}=30)\end{array}$ & $\begin{array}{c}\text { GROUP F } \\
(\mathrm{n}=30)\end{array}$ & P VALUE \\
\hline NAUSEA & $3(10 \%)$ & $2(6.67 \%)$ & 0.643 \\
\hline HYPOTENSION & $3(10 \%)$ & $2(6.67 \%)$ & 0.643 \\
\hline BRADYCARDIA & $2(6.67 \%)$ & $1(3.33 \%)$ & 0.556 \\
\hline VOMITING & $1(3.33 \%)$ & $1(3.33 \%)$ & 1.000 \\
\hline PRURITIUS & 0 & 0 & \\
\hline SHIVERING & $1(3.33 \%)$ & $2(6.67 \%)$ & 0.556 \\
\hline
\end{tabular}

\section{Discussion}

Transurethral Resection of prostate for benign prostatic hypertrophy is frequently performed in elder patients with cardiovascular comorbidities and systemic diseases. Considering this, it is desirable to limit the spinal block level to as low as possible to avoid hypotension owing to high sympathetic block and also maintain required level of anesthesia.

For these reasons, local anesthetics combined with other drugs i.e,. an opioid (Fentanyl) or $\alpha$ - agonist (dexmedetomidine) have been used as adjuvants to provide synergestic analgesia and to reduce the dose of local anaesthetic used. Opioid like Fentanyl has been used as adjuvant most commonly nowadays to reduce the dose of intrathecal local anaesthetics and improve the block quality.

However some adverse effects are associated with the use of opioids such as urinary retention, pruritus, nausea, vomiting and respiratory depression. It has been found that dexmedetomidine prolong the post operative analgesia of local anesthetics with less side effects and is a very promising adjuvant to improve the quality of spinal anesthesia.

The comparative study was designed to evaluate the efficacy and characteristics of dexmedetomidine and fentanyl as adjuvants to local anesthetics during spinal anesthesia.

In this comparative study dexmedetomidine significantly prolonged the duration of sensory and motor block compared with fentanyl. Also the time to achieve maximum sensory level was less though not significant in dexmedetomidine group. There was a longer pain free period andpost operative analgesic requirement was late in Group D than Group F. In spite of certain biased hypothetication regarding pruritis there was no 
incidence of any pruritis or respiratory depression in any group.

Coombs et al first introduced the analgesic properties of $\alpha_{2}$ adrenergic receptor agonist during intrathecal injection. Subsequent studies have shown that the injection of intrathecal $\alpha_{2}$ adrenoceptoragonist is mainly achieved by inhibiting the release of $\mathrm{C}$ peptide transmitters and substance $\mathrm{P}$ and hyper polarizing post synaptic dorsal horn neurons and the analgesic effect has a good correlation with their binding affinity to the spinal $\alpha_{2}$ adrenergic receptors. Therefore dexmedetomidine as a highly selective $\alpha_{2}$ adrenoceptor agonist $\left(\alpha_{2 /} \alpha_{1}\right.$ 1600:1) has greater advantage in intrathecal injection. However there are some dose related side effects of $\alpha 2$ agonist (dexmedetomidine) i.e sedation and neurotoxicity. The dose of dexmedetomidene used in our study was at the end of dosing spectrum and didn't produce any sedative effects. The greatest concern of dexmedetomidine is neurotoxicity. It can cause moderate to severe demyelination of white matter when it was administered by epidural route at a dose of upto $10 \mu \mathrm{g} / \mathrm{kg}$ in rabbits However in an experiment with sheep dexmedetomidine (2.5$100 \mu \mathrm{g}$ ) intrathecal injection did not cause neurological deficits

In the systematic review by Abdallah and Brull ${ }^{1}$ doses of dexmedetomidine upto $0.2 \mu \mathrm{glkg}$ for intrathecal and $1 \mu \mathrm{g} / \mathrm{kg}$ for peripheral administration didn't produce any neurotoxic manifestations

\section{Limitations of our Study}

We could not perform a follow up for our patients to asses any signs of neurotoxicity or neurological deficits due to the use of dexmedetomidine in the study group

\section{Conclusion}

In conclusion when compared to fentanyl (25ug) we found that Dexmedetomidine $(5 \mu \mathrm{g})$ as adjuvant to $2 \mathrm{cc}$ of $0.5 \%$ isobaric levobupivacaine for intrathecal injection in TURP surgeries can statistically significantly prolong the duration of sensory and motor block as well as prolonged post-operative analgesia without significant hemodynam changes

\section{Acknowledgement}

Authors would like to acknowledge the guidance of our head of the department Dr. A. Satyanarayana; In charge professor Dr. Muralikrishna and associate professor Dr.Ramana Prasad in conducting the study

Financial support and sponsorship: Nil

Conflicts of interest: There are no conflicts of interest

\section{References}

1. Abdallah FW, Brull R. Facilitatory effects of perineural dexmedetomidine on neuraxial and peripheral nerve block, a systematic review and meta-analysis $\mathrm{Br}$. J. Anaesth .2013;110(6), 915-925

2. Chung F, Meze G. Factors contributing to a prolonged stay after ambulatory surgery, Anaes Analog 1999, 89(6), 1352-1359

3. Elia N, culebras X, Mazzac: Schiffer E et al Clonidine as an adjuvant to intrathecal local anesthetics for surgery, systematic review of randomized trials. Reg Anesthesia Pain medicine 2008. 33. 15967

4. Kerarrmoza, kayes, Turhanogius, OzyIlmazMA , Low dose bupivacainefentanyl spinal anesthesia for transurethtal prostatectomy, Anesthesia 2003;5:.526-30

5. Kanazi GE, Jabbour-khoury SI AJ Jazzar MD, Alameddline MM Al-Yamen R, et al Effect oflow dose dexmedetomidine or clonidine on the charecteristics of bupivacaine spinablock. ACT Aaneesthesiolsc and 2006.50.222-7

6. Asano T.Dohi S;:Ohtas; Shimonakoh, Lidah, antinociception by epidural and systemic alpha (2)-adrenoceptor agonists and their binding affinity in rat spinal cord and brain Anesth Analg 2000:90:400-7 
7. Akcaboy Ey, Akcaboy ZN; Gogus N Low dose levobupivacaine $0.5 \%$ with fentanyl in spinal anesthesia for transurethrel resection of prostrate surgery. J.Res Med Sci 2011;16,68-73

8. Al-mustafa MM, Abu-Halaweh SA, Aloweidi AS, Murshidi MM; Ammari BA, Awwad ZM et al Effect of dexmedetomidine added to spinal bupivacaine for urological procedures: Saudi Med J2009;30;365-70

9. Gupta R Bogra J; Varrma R, Kohli M , kushwaha J K, Kumar $\mathrm{S}$ et el Dexmedetomidine as anintrethecal adjuvant for post operative analgesia Indian $\mathrm{J}$ anesthesia 2011: 55;347-51

10. Shukla D; Varma Agarwala, Pandey HD, Tyagi C, Comparitive study of intrathecal dexmeditomedine with intrathecelmagnesirm sulphate used as adjuvants to Bupivacaine J Aneesthesiolclinpharrmacol 2011;27:495-9

11. Hala EE, Mohammed SA, Hendy Dose related prolongation of hypebaric bupivacaine spinal anesthesia by dexmedetomidine Ain shams $\mathrm{j}$ anesthesiol 2011:4:83-95

12. Kim JE; kim NY,Lee HS; kil HK Effects of intrathecal dexmedetomidine on low dose bupivacaine spinal anesthesia in elderly patients undergoing transurethral prostatectomy Bio pharm bull2013:36:959-65

13. Talke PO Caldwell JE; Richardson CA kirkegaard-Niclsan H, Stafford M. The effects dexmedetomidine on neurornuscular blockade in human volunteers. Anesthanalg 1999:88:633-9
14. Basuni

AS,

Ahmed

Ezzha

Dexmedetomidine as supplement at low dose levobupivacaine spinal anesthesia for knee arthroscopy. Egyptian Journal of anesthesia 2014:30(2):149-153

15. Suresh G, Prasad CG, A comparative study of intrathecal $0.5 \%$ hyperbaric bupivacaine with dexmedetomidine and $0.5 \%$ hyperbaric bupivacaine with fentanyl for lower abdominal surgeries. Srilankan Journal of Anesthesiology 2016:2(1)2227

16. Liz, TianM, Zhang CY et el A randomised controlled trlal to evaluate the effectiveness ofintrethecal bupivacaine comblnedwith different adjuvants (fentanyl, clonidine and dexmedetomidine) in cesarean sections 2015;65(11):581586

17. Al- Ghanem SM ,Massad IM, Al Mustafa MM et el. Effect of adding dexmedetomidine versus fentanyl to intrathecal bupivacaine on spinal block, charecteristics in gynaecological procedures, a double blind controlled study, American Journal of applied sciences 2009:6(5):882-887

18. Eisenech JC,Shafer SL,1 Bucklin BA, Jackson C, kallion, pharmacokinetics and pharmacodynamics of intraspinal dexmedetomidine in sheep anesthesiology 1994:80(6):1349-1359

19. Hong JY, kimwo, Yoony, Choiy, kim SH, kil HK Effects of intravenous dexmedetomedine onlow dose bupivacaine spinal anesthesia in elderly patients , ACTA Aneesthesiol scand 2012:56(3)382387. 